\title{
IRONY COMPREHENSION IN THE NONNATIVE LANGUAGE COMES AT A COST
}

\begin{abstract}
Irony as a communicative phenomenon continues to puzzle. One of the key questions concerns cognitive and linguistic mechanisms underpinning irony comprehension. Empirical research exploring how much time people need to grasp irony as compared to literal meanings, brought equivocal answers. In view of the timespan-oriented-approach' inconclusiveness, we set to explore the efficiency of irony online processing in a limitedresponse-time paradigm. Additionally, we aimed to find out whether advanced nonnative users of a language, who have mastered ironic mode of thinking in their native language, get irony as efficiently in their nonnative as they do in their native language. Results show that participants were less efficient in processing irony than nonirony in both tested languages, yet the efficiency decreased in their nonnative language. These results license a claim that irony is a cognitively more demanding communicative phenomenon than literal meaning, and the effort invested in its comprehension increases in the nonnative language. Key words: irony, literal meaning, on-line processing, latency, accuracy, (non)/native language
\end{abstract}

\section{Introduction}

\section{Irony Processing Research Review - Monolingual Account}

Numerous attempts at explaining cognitive mechanisms underlying irony comprehension and its on-line processing have been undertaken. A range of theoretical accounts was formulated to explain irony as a linguistic, cognitive, affective and social phenomenon, elucidating numerous ways irony can be traced in language, thought, and culture (e.g., Alba-Juez \& Attardo, 2014; Barbe, 1995; Burgers, van Mulken, \& Schellens, 2012; Clark \& Gerrig, 1984; Filik,

Address for correspondence: Katarzyna Bromberek-Dyzman, Adam Mickiewicz University, Faculty of English. E-mail: kasia.dyzman@wa.amu.edu.pl 
Hunter, \& Leuthold, 2014; Filik, Țurcan, Thompson, Harvey, Davies \& Turner, 2016; Gibbs, 1986, 1994; Gibbs \& Colston, 2007; Kapogianni, 2016; Kreuz \& Glucksberg, 1989; Kumon-Nakamura, Glucksberg \& Brown, 1995; Muecke, 1970; Sperber \& Wilson, 1981, 1986, 1995). Ample empirical attempts were undertaken to grasp and explain behavioral and neural mechanisms underpinning irony comprehension, especially the interaction between literal and nonliteral language in irony comprehension (e.g., Colston, 2002, 2002; Filik \& Moxey, 2010; Gibbs, 1986, 2000; Giora, 1995, 1997, 2003; Kihara, 2005; Kotthoff, 2003; Partington, 2007; Regel, Coulson \& Gunter, 2010 Shelley, 2001; Shibata, Toyomura, Itoh, \& Abe, 2010; Uchiyama, Seki, Kageyama, Saito, Koeda, \& Sadato, 2006; Wakusawa, Sugiura, Sassa, Jeong, Horie, Sato, \& Kawashima, 2007; Spotorno, Cheylus, Van Der Henst, \& Noveck, 2013). So far, these attempts have described the multifaceted nature of ironicity, but have not explained its underlying mechanisms in communication or comprehension. On top of that, all these attempts without exception have studied irony comprehension in monolingual populations, focusing exclusively on the native language of study participants.

In the present study, we examine a rather unexplored aspect of cognitive effort in irony comprehension - its efficiency, and specifically, the accuracy of irony online processing in a population of nonnative users of English. Our main interest is in answering the question whether advanced users of a foreign language who have mastered ironic mode of thinking in their native language, get irony as efficiently (accurately and quickly) as they do in their native language.

In empirical studies, irony is commonly defined as a figurative mode of meaning in which literal meaning is juxtaposed with its nonliteral equivalent (e.g. Barbe 1995; Sperber and Wilson 1981). As an outcome of this literal and nonliteral meaning distinction in empirical research on irony, two differential processing modes have been postulated as instrumental for the processing of ironic versus literal language. Two major empirical paradigms strive to account for irony comprehension and on-line processing. While two-stage models assume that literal meaning is salient, and therefore, is accessed and processed faster than ironic meaning, one-stage models posit that given sufficiently constraining context, irony may be processed as fast, or faster than the literal meaning.

Two-stage models presuppose sequential access to ironic meaning. First, literal meaning is accessed. If it is revealed to be contextually unfit, literal meaning is revised and the nonliteral meaning is accessed. Two models, the standard pragmatic model (Grice, 1975) and its revised version- the graded salience hypothesis (Giora, 1995, 1997, 2002, 2003; Giora \& Fein, 1999; Giora, Fein, \& Schwartz, 1998; Giora, Fein, Laadan, Wolfson, Zeituny, Kidron, \& Shaham, 2007) are most representative of the two-stage account. They each hold that in understanding figurative language, literal/salient meaning is determined before 
the nonliteral/nonsalient one. While the processing of irony requires backtracking and reinterpretation, literal/salient meaning processing does not. Two-stage models predict that irony comprehension, due to the extra processing effort involved in backtracking and reinterpretation, takes longer to process than the literal (salient, coded) interpretations do. A number of empirical studies confirm two-stage irony processing assumptions and provide experimental evidence showing significant response latency delays in irony processing as compared to the equivalent literal language processing (e.g., Dews \& Winner, 1995, 1999; Filik \& Moxey, 2010; Giora, 1995, 1997, 2002, 2003; Giora \& Fein, 1999; Giora et al., 1998; Giora et al., 2007; Schwoebel, Dews, Winner, \& Srinvas, 2000). These results, demonstrating that irony processing takes longer than literal meaning processing, are interpreted as evidence for the primacy of literal/salient meaning processing over the nonliteral/figurative meaning.

One-stage models (e.g., Gibbs, 1986, 1994, 2004; Sperber \& Wilson, 1981, 1986, 1995; Wilson \& Sperber, 2004, 2012) presume processing equivalence for the literal and nonliteral meanings. In this view, understanding nonliteral language does not require any special processes other than those involved in literal language comprehension. Processing equivalence models highlight the primary role of contextual effects in comprehension, and posit a universal comprehension mechanism that is sensitive to both linguistic (literal and nonliteral) and contextual (nonlinguistic) information irrespective of literality or figurativeness of an utterance. Consequently, one-stage models posit direct access to appropriate literal or nonliteral meaning provided the message is proffered in a sufficiently supportive context. Context allows pragmatic meaning to be tapped directly. According to Gibbs (1994), recognition of incongruity between what people say and what they mean reflects the cognitive ability of people to think ironically. Therefore, understanding irony requires neither special cognitive processes nor extra effort. A number of empirical studies validate one-stage irony processing assumptions, showing that irony processing does not take longer than nonironic language processing (e.g., Gibbs, 1986, 1994; 2000; Gibbs \& O’Brien, 1991; Gibbs, O’Brien, \& Doolittle, 1995; Ivanko \& Pexman, 2003). In fact, Gibbs (1986) found that in irony-normative contexts, where negatively valenced situational features cue expectation for undesirable outcome, irony is processed faster than nonironic equivalents. These results were taken to validate the claim that irony processing does not necessarily take longer than nonirony processing, and people do not need to process the literal meaning of ironic expressions prior to deriving their nonliteral interpretations. On top of that, Gibbs' (1986) results are taken as evidence that it is not the literality or nonliterality of meaning that is crucial in irony comprehension, but the context.

Context and its crucial role in expectation cueing and guiding comprehension has been widely noticed (e.g., Bar 2011; Barrett, Mesquita, \& Smith 2010; Federmeier, 2007; Higgins 1998; Sperber \& Wilson, 1986, 1995; Van Berkum, 
2010; Wilson \& Sperber, 2004). Utsumi (2000) emphasizes that the disparity between the speaker's failed expectations and the actual situational or communicative outcome is one of the key issues connected with irony comprehension. Irony hinges on failed expectation as its basic, defining feature (e.g., Attardo, 2000; Clark \& Gerrig, 1984; Dews \& Winner, 1995, 1999; Kreuz \& Glucksberg, 1989; Kumon-Nakamura et al., 1995; Sperber \& Wilson, 1981, 1986, 1995; Utsumi, 2000). Failed expectations in ironic utterances are featured through context-utterance incongruity. For example, a negative context vis a vis a positive comment following it, gives rise to ironic criticism. A negatively framed, unfavorable situational context calls for and stirs expectation for criticism. If literal praise is employed to comment on the situation instead, this gives rise to critical irony. This type of context-comment incongruity might trigger two incompatible interpretations in hearers: a literal interpretation (context-incongruent) and an ironic interpretation (context-congruent).

The issue of irony perception and comprehension in varying degrees of situational incongruity has been studied by Gerrig and Goldvarg (2000). Their research shows that the greater the situational incongruity, the higher the perception of irony. Situations with smaller degrees of incongruity, in the experimental conditions studied by Gerrig and Goldvarg, did not lead to a higher perception of irony. Similar results clearly indicating the effect of incongruity on irony perception have been obtained by Colston and O'Brien (2000). Examining the pragmatic functions of strong and weak ironic statements in contexts with various degrees of contrast between the situational context and an ironic statement, Colston and O'Brien found that perception of irony is directly related to the degree of context-statement incongruity. Exploring how contrast and assimilation effects influence the interpretation of irony, Colston (2002) found that the degree of strength of positivity or negativity of context in which a communicative situation is set, cues hearers' expectations as to the type of comment likely to follow the situation. Colston observed that contrast effects emerge in situations in which there is a strong discrepancy between the negative context and the statement that comments on it. A smaller context-statement discrepancy evokes an assimilation effect and is perceived as less negative by the respondents. Following Colston's observations on contrast and assimilation effects and their influence on the perception and interpretation of irony, Ivanko and Pexman (2003) examined how the varying degrees of context-statement incongruity affect irony processing. Results of the experiments carried out by Ivanko and Pexman clearly indicate that various degrees of contextual strength and the ensuing varying degrees of context-statement incongruity play a vital role in irony processing. Ivanko and Pexman observe that the degree of negativity of the contextual situation in which irony is embedded has a direct bearing on the subjects' response latencies in on-line irony processing. Their study shows that the degree of context negativity (strongly negative, weakly negative, and neutral 
context) has a differential impact on the ensuing comment processing. In their study, a weakly negative context facilitated irony processing. A strongly negative and a neutral context delayed ironic comments processing. These results show that irony processing, as compared to literal statement processing, might be as fast as, or even occasionally faster than literal comments processing, provided that context is moderately negative. In this way, they point to the significance of contextual incongruity, especially the degree of situational negativity, as a reliable factor underpinning the ensuing comment expectancy and, in result, modulating the time course of irony processing.

Whether there is a sequence or simultaneity in mental operations connected with irony processing remains an issue open to experimental investigation. What seems unquestioned is the conviction that both literal and nonliteral meaning is essential for irony comprehension and both are accessed in irony computation (e.g., Dews and Winner 1995, 1999; Schwoebel et al., 2000). The extant experimental research on irony processing is inconclusive in terms of whether the entire literal meaning of an ironic utterance is processed or just some part of it, and whether the literal meaning is processed before, after, or simultaneously with the nonliteral meaning. Likewise, it has not been established whether the nonliteral and literal meaning access and processing are a fixed pattern in irony comprehension, or a tendency stemming from either lexical (e.g., Giora, 1995, 1997, 2002; Giora \& Fein, 1999; Giora et al., 1998) or contextual (e.g., Gibbs, 1986, 1994, 2001, 2002; Ivanko \& Pexman, 2003; Utsumi, 2000) salience.

\section{Irony Processing in the Non-monolingual Context}

So far, extant empirical research on irony processing has exclusively focused on monolinguals' pragmatic and figurative competence in irony comprehension. The aim of the present paper is to investigate irony processing in a nonmonolingual population of foreign language users vis a vis their processing of ironic and nonironic language in their mother tongue. Bromberek-Dyzman, Rataj, and Dylak (2010), in an irony processing, self-paced study, found no differences between the tested languages (Polish as L1 and English as L2) as far as the speed and accuracy of irony processing is concerned. Their results revealed convergent L1 and L2 irony processing patterns. No significant language differences (speed, accuracy) were observed. Participants processed irony in L2 no longer than in L1. They also did not make more errors when processing irony in L2 than in their L1. Yet, within-language analyses showed significant differences between irony and literal language conditions, demonstrating a longer response latency rate and higher error rate for irony than for literal language in L1 and L2, respectively. Response time was measured in milliseconds. Participants made significantly more errors in responses to ironic than literal sentences, both in Polish and English, and they were significantly slower in 
irony $(M=1540 \mathrm{~ms})$ than in literal utterance $(M=1239 \mathrm{~ms})$ processing. Very interestingly, the same patterns were observed for both languages. That study showed that in the self-paced processing condition, proficient L2 users did not require more time and did not make more errors when processing ironic sentences in L2 than in L1. One of the possible reasons for the lack of between-language differences might be the type of task used, that is, a self-paced reading procedure. Since such procedures may not be sufficiently sensitive to find existing differences, we designed the current study to investigate whether between-language differences could be observed when a response window procedure is applied. This procedure, in which participants have limited time to respond, has previously been used in priming studies to increase sensitivity of the measures (Greenwald, Sean, Draine, \& Abrams, 1996). The present study is thus a follow-up on the previous study (Bromberek-Dyzman et al., 2010), aiming to examine irony processing in the participants' native (Polish) and their nonnative language (English) in a limited reading and responding condition, to further test whether, in restrictive timing conditions, irony comprehension patterns in participants' respective languages will still generate similar response patterns in terms of response latency and accuracy rates.

\section{Method}

\section{The Aim of the Study}

The present study aimed to test irony processing in the participants' native (Polish) and nonnative (English) languages. Our overall goal was to find out whether in constrained reading and responding time, the speed and accuracy of irony comprehension in the participants' native and nonnative language, will be similar or will differ between the languages. The previous study results indicated that good knowledge of the nonnative language makes language users equally capable of accurate and speedy irony comprehension in both languages. In the present study we seek to find answers to the following questions: Are literal meanings processed as accurately, and as fast in the nonnative as in the native language? Are ironic meanings processed as accurately, and as fast as literal meanings in both tested languages? The present study imposes constrained reading and responding timing, which may result in a decrease in the accuracy rate especially in irony trials. Irony comprehension involves ambiguity and incongruity recognition and resolution, which costs processing time. Research shows that in a limited time condition, subjects striving for speeded responses sacrifice accuracy (see Reed, 1973). Therefore, we expect a drop in accuracy for irony. The drop, we hypothesize, will be steeper for L2 than L1, due to extra processing effort involved in the nondominant language access (see Kroll \& Steward 1994). For the response latency, as a corollary of the measure, we neither expect L1/L2 nor irony/nonirony differences. 


\section{Participants}

Fifty-six Polish students in the 3-year B.A. program at the Adam Mickiewicz University Faculty of English in Poznan ( $M_{\text {age }}=21.9$ years; 42 women and 14 men) volunteered to participate in the study. All of the participants were native speakers of Polish, highly proficient in English (CPE level).

\section{Materials}

The pre-experimental stimulus pool consisted of 120 situational scenarios and 120 distractor (filler) trials, whose function was to deter participants from forming hypotheses, and judging the comments in an automatic manner. For this purpose distractor trials featured two types of figurative language metaphors and idioms, as well as literal meanings. Fillers were not included in the analyses.

Each trial consisted of a 2-3 sentence mini-story featuring an interaction between two acquaintances. All the mini-stories ended with one character commenting either ironically (ironic criticism) or literally (literal praise) on the topic of the story. The remarks were designed to sound as natural as possible, for both literal and ironic comments. Prior to the experimental study, two norming studies were carried out on the population of students from the 3-year B.A. program at the Faculty of English at the Adam Mickiewicz University not involved in the experiment proper.

The first norming task was a cloze test. Twenty participants (Faculty of English, 3-year B.A. program) aged 18-21, took part in this part of the study. The goal of this pre-test was to ensure that the situational contexts of the stories were strong enough to trigger expectations for positive and/or negative terminal words. Mini-stories featured situational contexts unambiguously calling for either criticism or praise. Participants were asked to complete the target sentences with one final word which, according to them, best fitted the featured situations. The two types of contextual frames were constructed so as to convey (a) a desirable situation calling for a praise (a positive context condition) and (b) an undesirable situation endorsing a criticism (a negative context condition). We wanted to verify whether the contextual setup featured in each story, and especially its situational undesirability or desirability, would gear participants to anticipate critical or praising comments, and whether the participants would complete the comment sentences embedded in positive (intended as literal compliments) and negative contexts (intended as ironic criticism) as they were expected. Half of the participants did the probability cloze test in English, half in Polish. Only stories whose comment sentences, in both language blocks respectively, were interpreted by all the respondents (100\% match) as calling for criticism or praise were selected for further testing. Based on this pre-test, we selected two sets (English and Polish) of experimental trials containing 
30 ironic and 30 literal trials for the English block, and 26 ironic and 26 literal trials for the Polish block. This norming study showed that in the off-line condition, contextually enhanced desirability or undesirability was a sufficient cue to trigger the expected interpretation of the comments.

In the second norming study, we aimed to test whether the comment sentences were interpreted by the participants as they were intended, i.e., as literal praise (positive comment) or ironic criticism (negative comment). To this aim, we asked participants to rank a comment sentence in each scenario according to whether it expressed a favorable (e.g., "He would never break the law, or do anything illegal. He seems so honest.", literal praise) or unfavorable opinion (e.g., "He was looking for a better paid job. And when he was offered an excellent job, he didn't bother to take it. He is so clever., ironic criticism). Participants were asked to indicate their judgments on a seven-point scale ranging from 1 (very positive) to 7 (very negative). Thirty Polish students (Faculty of English, 3-year B.A. program), aged 18-21, volunteered to participate in the task. 16 participants rated the comments in English and 14 in Polish. A paired sampled $t$ test was conducted separately for each language, to compare participants' judgments of the two types of comment sentences. As predicted, ironic comments in Polish $(M=6.04, S D=0.589)$ were evaluated as more negative than literal comments $(M=2.35, S D=0.46),[t(13)=15, p<0.001]$. For English, the pattern of results was similar with ironic comments $(M=6.03, S D=0.22)$ rated as more negative than literal comments $(M=1.83, S D=0.34),[t(15)=33$, $p<0.001]$. This pre-test demonstrated that in an off-line condition, participants successfully evaluated the intent of the comment sentences as expected.

Our experimental stimuli featured two situational context conditions: a positive one, building an expectation for a desirable comment, and a negative one, triggering an expectation for an undesirable comment. Two comment types were used: literal praise in a desirable context condition, and ironic criticism in an undesirable context condition. A comment sentence always expressed literal praise, but depending on the preceding context it either conveyed a literal praise (congruity condition) or an ironic criticism (incongruity condition). Comment sentences exhibited one type of syntactic structure: subject + predicate be + complement. The word that imposed the intended interpretation on the comment sentence was the terminal adjective. The target adjectives were controlled for frequency $\left(M_{\mathrm{PL}}=35.6, S D=21.4 ; M_{\mathrm{ENG}}=32.9, \mathrm{SD}=16.1\right)$ and syllable length. Polish pool of adjectives was selected from Polish language corpus (Korpus Języka Polskiego PWN) and English pool came from English language corpus (British National Corpus). Sample stories are included in Table 1 below.

\section{Procedure}

Participants were tested individually in a soundproof room. A session for a single participant lasted approximately $20 \mathrm{~min}$. Participants were seated at the 
Table 1. Sample Stories

Congruity condition: Positive context and positive comment (literal praise)

A: When he says he will help, he will help. He keeps his promises.

B: He has always been ... reliable.

A: He is always very precise with money. He knows exactly how much he spends on living.

B: He is very ... accurate.

Incongruity condition: Negative contexts and positive comments (ironic criticism)

A: He kept promising assistance in difficult cases. He did not try to help me even once.

B: He has always been ... reliable.

A: He never counts how much money he spends on gambling. Yet, he knows exactly how much I spend on cosmetics.

B: He is very ... accurate.

\section{Filler stories}

A: The exam session this semester was quite demanding. I haven't failed any exam this session.

B: You're doing pretty ... bad.

A: She won the scholarship competition. She heads for Norway next month.

B: She's on cloud ... nine.

computer and told that their task was to read the stories and judge the remarks presented on the computer screen for whether the speaker communicated a praising, or a critical comment. Participants were told to take into account the entire communicative interaction and indicate their interpretive decisions as quickly and accurately as possible by pressing one of two labeled keys. Handedness was controlled for and counterbalanced between subjects. Participants' responses and response times were recorded by E-Prime 2.0 (Schneider, Eschman, \& Zuccolotto. 2002). The session began with 12 practice blocks to familiarize participants with the experimental task. After the practice block, there was a break, during which the experimenters ensured whether the instructions were clear and whether the participants knew when and how to indicate their decisions. There were two blocks in the experimental session - English and Polish stimuli 
were presented in separate blocks. The order of block presentation was counterbalanced, so that half of the participants completed the English block first while the other half completed the Polish block first. Each participant judged 30 experimental trials (15 literal, 15 ironic) in English and 26 experimental trials in Polish (13 literal, 13 ironic), plus 30 filler trials. No participant saw the same comment twice. The order in which the items were presented was randomly determined by the computer software (E-Prime 2.0).

At the beginning of each trial, a fixation cross appeared in the center of the computer screen for $500 \mathrm{~ms}$. After the fixation cross disappeared, the introductory sentence - story context - appeared on the screen. The context remained on the screen for $3500 \mathrm{~ms}$, after which time it was replaced with the target sentence, presented without the terminal word. This part of the story was displayed also for a fixed timespan of $900 \mathrm{~ms}$. Both time display limits (3500 ms, $900 \mathrm{~ms}$ ) were established based on the self-paced study results (Bromberek-Dyzman et al., 2010) and were additionally pilot-tested before the experiment proper. The onset of the decision time was marked by the appearance of the target word. The response window procedure developed by Greenwald et al. (1996) was employed. The response window procedure imposes a speed versus accuracy trade-off (Reed, 1973) in eliciting responses in order to limit strategic processing and responding. With the constrained processing and response time limits, the procedure enables to index processing patterns in restricted processing conditions. Participants were required to respond within a $1 \mathrm{~s}$ time window that began with the target onscreen onset. Within this timespan, participants were asked to decide whether the opinion expressed in the comment (target sentence) was positive (literal praise condition) or negative (irony condition). They were cautioned to make their judgments taking into account the entire communicative scenario. Participants were instructed to respond as fast and as accurately as possible. If they did not manage to respond within the $1 \mathrm{~s}$ timespan, the response was interpreted as a timeout error. No feedback on response accuracy was provided.

\section{Results}

The data in this experiment were accuracy rates and response latencies in Polish and English for literal meaning (literal praise) and ironic meaning (critical irony). Both types of meaning were expressed via identical positively worded utterances, which communicate praise in positive situational contexts (e.g., "That's just great!") and criticism in negative situational contexts. Data from 17 subjects were excluded from further analyses due to low accuracy rates and response times deviating by at least $2.5 \mathrm{SDs}$ from the group mean. To test for potential differences in irony processing between participants' L1 and L2, the obtained data with factors of language (English vs. Polish) and utterance type (irony vs. literal) were subjected to 2 two-way repeated-measures ANOVAs 
on reaction times and accuracy rates. The analysis on reaction times was performed only for correct responses. Comparative analyses were run for identical target sentences intended either literally or ironically in both language blocks.

Accuracy rates data. A $2 \times 2$ (Language [English, Polish] $\times$ Utterance Type [ironic, literal]) repeated-measures ANOVA on accuracy rates revealed a significant language effect, $\left[F(1,38)=7.13, p=0.011, \eta_{\mathrm{p}}{ }^{2}=0.16\right]$, a significant utterance type effect, $\left[F(1,38)=15.48, p<0.001, \eta_{\mathrm{p}}{ }^{2}=0.29\right]$, and a significant interaction between these two variables $\left[F(1,38)=13.81, p=0.001, \eta_{\mathrm{p}}{ }^{2}=0.27\right]$. Post hoc tests showed that while there was no statistically significant difference in accuracy rates in interpreting literal utterances in Polish $(M=80.0, S D=13.07)$ and English $(M=82.05, S D=8.40),[p>0.05]$, significantly lower accuracy was observed in responses to ironic utterances in English $(M=60.17, S D=24.25)$, $[p<0.001]$. Also, a significant accuracy rate difference was observed for ironic $(M=60.17$, $S D=24.25)$ and literal trials $(M=82.05, S D=8.40),[p<0.0001]$ in English. This suggests that, although study participants were highly proficient in English, which shows in the results for the literal utterances' judgments across languages, they still experienced significant difficulty evaluating ironic utterances in English. The nonnative language showed more demanding in this respect than the native language. These results demonstrate that in limited response time, on-line irony computation in participants' nonnative language poses more processing demands than literal language interpretation. Mean accuracy rates are provided in Table 2 below.

Table 2. The Mean Accuracy Rates for Utterance Type and Language

\begin{tabular}{lcccc}
\hline & \multicolumn{2}{c}{ Ironic } & \multicolumn{2}{c}{ Literal } \\
\hline & $\boldsymbol{M}$ & $\boldsymbol{S D}$ & $\boldsymbol{M}$ & $\boldsymbol{S D}$ \\
\hline Polish & 73.85 & 20.94 & 80.00 & 13.07 \\
English & 60.17 & 24.25 & 82.05 & 8.40 \\
\hline
\end{tabular}

Response time data. A $2 \times 2$ (Language [English, Polish] $\times$ Utterance Type [ironic, literal]) repeated-measures ANOVA revealed a main effect of utterance type, $\left[F(1,37)=11.16, p<0.01, \eta_{\mathrm{p}}{ }^{2}=0.23\right]$. Despite an observed trend $(F(1,37)=3.57$, $\left.p=0.067, \eta_{\mathrm{p}}{ }^{2}=0.09\right)$ to respond to English stimuli longer than to Polish ones, the response time data did not show a language effect. The interaction effect did not reach significance. Mean response times are provided in Table 3 below. 
Table 3. The Mean Response Times (in Milliseconds) for Utterance Type versus Language Type

\begin{tabular}{lcccc}
\hline & \multicolumn{2}{c}{ Ironic } & \multicolumn{2}{c}{ Literal } \\
\hline & $\boldsymbol{M}$ & $\boldsymbol{S D}$ & $\boldsymbol{M}$ & $\boldsymbol{S D}$ \\
\hline Polish & 671.32 & 114.73 & 637.55 & 80.33 \\
English & 695.18 & 81.05 & 665.97 & 60.88 \\
\hline
\end{tabular}

\section{Discussion}

The goal of the present study was to explore irony processing in participants' native (Polish) and nonnative (English) language. The present study employed the response window procedure (Greenwald et al., 1996), forcing study participants to respond to experimental stimuli in limited time. This paradigm allows to control for the speed versus accuracy trade-off, and because the response time was brief $(1 \mathrm{~s})$, participants were expected to be prompt, yet less accurate, in their decisions. As a corollary of the forced response speed, we did not expect response time patterns to manifest significant differences between the studied languages and utterance types. Instead, we were interested in exploring whether the cognitive difficulty reported for irony response and reading time patterns (e.g., Dews \& Winner, 1995, 1999; Filik \& Moxey, 2010; Giora \& Fein, 1999; Giora et al., 1998; Giora et al., 2007; Schwoebel et al., 2000) would be manifested in accuracy drop patterns.

Accuracy rates data show accuracy drop. Judging ironic criticism as the intended meaning, posed more difficulty than judging the literal, praising meaning intended by the speaker literally. One possible reason for the observed effect and its partial explanation is the employment of the response window procedure which enforced speed versus accuracy trade off. By necessitating a fast response, the procedure enhanced higher error rates. By limiting the response time to only $1 \mathrm{~s}$, we forced participants to focus on the speed of response rather than accuracy, which most likely contributed to the drop in accuracy.

Higher response accuracy was observed for the evaluatively congruent trials (literal praise condition) than for the incongruent ones (critical irony condition). This is a telling, yet expected result. The low accuracy rate result may also stem from the nature of the task. Unlike judging the literal meaning - a relatively unambiguous task, judging ironic meaning, which employs a praising comment to convey criticism, poses an interpretive challenge that costs time. Since the 
processing time and response time were limited, the increased processing cost showed in high error rates (see Dews \& Winner, 1999). The $1 \mathrm{~s}$ timespan allowed in this timed task, may not have been sufficient for all participants to resolve the intended meaning ambiguity in ironic comments, which literally communicate praise, yet situationally carry a critical opinion that manifests the speaker's dissatisfaction with the situation at hand. Participants made more errors when responding to irony than to literal stimuli in both languages. The higher error rates noted for ironic trials in both languages, when compared to literal trials, are viewed as indicative of increased processing demands. This might be a corollary of increased difficulty that needs to be invested in irony comprehension. We found a drop in accuracy rates for irony both within and between languages, yet the number of errors increased for English. Interestingly, this increase in errors in participants' L2 seems to be directly related to irony processing, as the difference between L1 and L2 for literal trials was not observed.

The results obtained in this study are consistent with the previous research on irony processing (e.g., Dews \& Winner, 1995, 1999; Filik \& Moxey, 2010; Giora \& Fein, 1999; Giora et al., 1998; Giora et al., 2007; Schwoebel et al., 2000) not only in showing that irony comprehension elicits more effort than literal utterances, observed in accuracy drop, but also in longer response latency patterns evidenced for irony computation. These longer response latency patterns were registered for both languages. Despite an observed tendency to respond to English stimuli slower than to Polish ones, the response time data did not show a language effect. This means that participants were slower in responding to ironic stimuli in Polish and English alike. As the language effect was not found significant, demonstrating only a tendency to process Polish stimuli faster than English, we interpret this result as an indication of an increased processing demand for irony, irrespective of the language at hand. This is an interesting result, indicating that irony processing in one's nonnative language might be as fast as in one's native language, provided that one's command of both languages is proficient. Also, this result may be taken to corroborate Gibbs' (1994) claim that irony is a mode of thought: a way of conceptualizing one's attitude, or a fundamental figure in the poetics of mind via which we conceptualize events, and experiences as ironic. Language merely reflects this figurative mode of thinking. So, if we constrain irony as a mode of thinking, a fundamental way of conceptualizing attitudes to events, experiences, or people, the language in which one frames one's thoughts - native or nonnative (provided one knows the language sufficiently well to communicate one's attitudes), is not a determining factor in irony comprehension (see Bromberek-Dyzman, 2014).

The data obtained in this study may also be viewed as a corollary of the differential processing patterns underpinning evaluative congruity and incongruity computation. In line with Colston and Gibbs (2002), we may say that literal and ironic comments necessitate differential processing modes. While processing 
evaluative congruity (positive context followed by literal praise) generated a processing advantage observed by high accuracy rate and shorter response time, the computation of evaluative incongruity (negative context followed by literal praise, i.e., ironic criticism) produced a higher error rate and delayed responding. In line with this approach, different processing patterns obtained for ironic and literal stimuli may be stemming from the differential expectation consistent (literal praise) and an expectation-inconsistent (ironic criticism) processing modes.

\section{Conclusion}

The present study shows that irony processing in timed response window generated more errors, and lasted longer when compared to literal comments, and the processing cost increased in the nonnative language. These results might be taken to indicate that those who have mastered ironic mode of thinking, are successful in detecting irony in their respective languages, albeit at higher cognitive cost/effort in the nonnative, or nondominant language. Yet, to make stronger claims about the role of native/nonnative language in irony processing, further research needs to account for a wider variable range in both literal and irony conditions, and more diversified processing time conditions (see Bromberek-Dyzman 2014, 2015).

\section{References}

Alba-Juez, L. \& Attardo, S. (2014). The evaluative palette of verbal irony. In G. Thompson \& L. Alba-Juez (Eds.), Evaluation in Context (pp. 93-116). Amsterdam: John Benjamins.

Attardo, S. (2000). Irony as relevant inappropriateness. Fournal of Pragmatics, 32 (6), 793-826.

Bar, M. (Ed.) (2011). Predictions in the Brain. Using Our Past to Generate a Future. Oxford: Oxford University Press.

Barbe, K. (1995). Irony in Context. Amsterdam: John Benjamins.

Barrett, L.F., Mesquita, B., \& Smith, E.R. (2010). The Context Principle. In B. Mesquita, L.F. Barrett, \& E.R. \& Smith (Eds.), The Mind in Context (pp. 1-24). New York, NY: The Guilford Press.

British National Corpus (2010). Oxford: Oxford University Press.

(http://sara.natcorp.ox.ac.uk)

Bromberek-Dyzman, K. (2014). Attitude and Language: On explicit and implicit attitudinal meaning processing. Poznań: Wydawnictwo Naukowe UAM.

Bromberek-Dyzman, K. (2015). Irony Processing in L1 and L2: Same or different? In R.R. Heredia \& A. Cieślicka (Eds.), Bilingual Figurative Processing Language (pp. 215-240). New York, NY: Cambridge Universiyty Press. 
Bromberek-Dyzman, K., Rataj, K., \& and Dylak, J. (2010). Mentalizing in the second language: Is irony online inferencing any different in L1 and L2? In I. Witczak-Plisiecka (Ed.), Pragmatic Perspectives on Language and Linguistics; Vol.1: Speech Actions in Theory and Applied Studies (pp. 197-216). Newcastle, UK: Cambridge Scholars Publishing.

Burgers, C., van Mulken, M., \& Schellens, P.J. (2012). Type of evaluation and marking of irony: The role of perceived complexity and comprehension. fournal of Pragmatics, 44 (3), 231-242.

Clark, H. \& Gerrig, R. (1984). On the pretense of irony. Journal of Experimental Psychology: General, 113 (1), 121-126.

Colston, H.L. (2002). Contrast and assimilation in verbal irony. Journal of Pragmatics, 34 (2), 111-142.

Colston, H.L. \& Gibbs, R.W. (2002). Are irony and metaphor understood differently? Metaphor and Symbol, 17 (1), 57-80.

Colston, H.L. \& O’Brien, J. (2000). Contrast of kind versus contrast of magnitude: The pragmatic accomplishments of irony and hyperbole. Discourse Processes, 30 (2), 179-199.

Dews, S. \& Winner, E. (1995). Muting the meaning: A social function of irony. Metaphor and Symbolic Activity, 10 (1), 3-19.

Dews, S. \& Winner, E. (1999). Obligatory processing of literal and nonliteral meanings in verbal irony. Journal of Pragmatics, 31 (12), 1579-1599.

Federmeier, K. (2007). Thinking ahead: The role and roots of prediction in language comprehension. Psychophysiology, 44 (4), 491-505.

Filik, R. \& Moxey, L.M. (2010). The on-line processing of written irony. Cognition, $116(3), 421-436$.

Filik, R., Leuthold, H., Wallington, K., \& Page, J. (2014). Testing Theories of Irony Processing Using Eye-Tracking and ERPs. Fournal of Experimental Psychology: Learning, Memory, and Cognition, 40 (3), 811-828.

Filik, R., Țurcan, A., Thompson, D., Harvey, N., Davies H., \& Turner A. (2016). Sarcasm and emoticons: Comprehension and emotional impact. The Quarterly Journal of Experimental Psychology, 69 (11), 2130-2146.

Gerrig, R. \& Goldvarg, Y. (2000). Additive effects in the perception of sarcasm: Situational disparity and echoic mention. Metaphor and Symbol, 15 (4), 197-208.

Gibbs, R.W.Jr. (1986). On the psycholinguistics of sarcasm. Fournal of Experimental Psychology: General, 115 (1), 3-15.

Gibbs, R.W.Jr. (1994). The Poetics of Mind: Figurative Thought, Language and Understanding. Cambridge, MA: Cambridge University Press.

Gibbs, R.W.Jr. (2000). Irony in talk among friends. Metaphor and Symbol, 15(1-2), 5-27.

Gibbs, R.W.Jr. (2001). Evaluating contemporary models of figurative language understanding. Metaphor and Symbol, 16 (3/4), 317-333.

Gibbs, R.W.Jr. (2002). A new look at the literal meaning in understanding what is said and implicated. Fournal of Pragmatics, 34 (4), 457-486. 
Gibbs, R.W.Jr. (2004). Psycholinguistic experiments and linguistic pragmatics. In I. Noveck \& D. Sperber (Eds.), Experimental Pragmatics (pp. 50-71). New York, NY: Palgrave Macmillan.

Gibbs, R.W.Jr. \& O’Brien, J.E. (1991). Psychological aspects of irony understanding. Journal of Pragmatics, 16 (6), 523-530.

Gibbs, R.W.Jr., O’Brien, J.E., \& Doolittle, S. (1995). Inferring meanings that are not intended: Speakers' intentions and irony comprehension. Discourse Processes, 20 (2), 187-203.

Gibbs, R.W.Jr. \& Colston, H. (Eds.). (2007). Irony in Language and Thought. New York, NY: Lawrence Erlbaum Associates.

Giora, R. (1995). On irony and negation. Discourse Processes, 19 (2), 239-264.

Giora R. (1997). Understanding figurative and literal language: The graded salience hypothesis. Cognitive Linguistics, 8 (3), 183-206.

Giora, R. (2002). Literal vs. figurative language: Different or equal? fournal of Pragmatics, 34 (4), 487-506.

Giora, R. (2003). On Our Mind. Oxford, UK: Oxford University Press.

Giora, R., Fein, O., \& Schwartz, T. (1998). Irony: Graded salience and indirect negation. Metaphor and Symbol, 13 (2), 83-101.

Giora, R. \& Fein, O. (1999). Irony: Context and salience. Metaphor and Symbol, 14 (4), 241-257.

Giora, R., Fein, O., Laadan, D., Wolfson, J., Zeituny, M., Kidron, R., Shaham, R. (2007). Expecting irony: Context versus salience-based effects. Metaphor and Symbol, 22 (2), 119-146.

Greenwald, A., Sean, G., Draine, C., \& Abrams, R.L. (1996). Three cognitive markers of unconscious semantic activation. Science, 273 (5282), 1699-1702.

Grice, P. (1975). Logic and conversation. In P. Cole \& J. L. Morgan (Eds.), Syntax and Semantics, Volume 3: Speech Acts (pp. 41-58). New York, NY: Academic Press.

Higgins, E.T. (1998). The Aboutness Principle: A Pervasive Influence on Human Inference. Social Cognition, 16 (1), 173-198.

Ivanko, S. \& Pexman, P.M. (2003). Context incongruity and irony processing. Metaphor and Symbol, 33 (3), 241-279.

Kapogianni, E. (2016). The ironic operation: Revisiting the components of ironic meaning. Journal of Pragmatics, 91, 16-28.

Kihara, Y. (2005). The mental space of verbal irony. Cognitive Linguistics, 16 (3), 513-530.

Korpus Języka Polskiego PWN. (http://korpus.pwn.pl/)

Kotthoff, H. (2003). Responding to irony in different contexts: On cognition in conversation. Journal of Pragmatics, 35 (9), 1387-1411.

Kreuz, R.J. \& Glucksberg, S. (1989). How to be sarcastic: The echoic remainder theory of verbal irony. Fournal of Experimental Psychology: General, 118 (4), 374-386. 
Kumon-Nakamura, S., Glucksberg, S., \& Brown, M. (1995). How about another piece of pie: The allusional pretense theory of discourse irony. Journal of Experimental Pragmatics: General, 124 (1), 3-21.

Muecke, D.C. (1970). Irony and the Ironic. London, UK: Methuen.

Partington, A. (2007). Irony and reversal of evaluation. Fournal of Pragmatics, 39 (9), 1547-1569.

Reed, A.V. (1973, August). Speed-accuracy trade-off in recognition memory. Science, 1 (181), 574-576.

Regel, S., Coulson, S., \& Gunter, T.C. (2010). The communicative style of a speaker can affect language comprehension? ERP evidence from the comprehension of irony. Bran Research, 1311, 121-135.

Schneider, W., Eschman, A., \& Zuccolotto, A. (2002). E-Prime Reference Guide. Pittsburgh, PA: Psychology Software Tools.

Schwoebel, J., Dews, S., Winner, E., \& Srinvas, K. (2000). Obligatory processing of the literal meaning of ironic utterances: Further evidence. Metaphor and Symbol, 15 (1/2), 47-61.

Shelley, C. (2001). The bicoherence theory of situational irony. Cognitive Science, 25 (5), 775-818.

Shibata, M., Toyomura, A., Itoh, H., \& Abe, J.I. (2010). Neural substrates of irony comprehension: A functional MRI study. Brain Research, 1308, 114-123.

Sperber, D. \& Wilson, D. (1981). Irony and the use-mention distinction. In P. Cole (Ed.), Radical Pragmatics (pp. 295-318). New York, NY: Academic Press.

Sperber, D. \& Wilson, D. (1986). Relevance. Communication and Cognition. Oxford, UK: Basil Blackwell.

Sperber, D. \& Wilson, D. (1995). Relevance: Communication and Cognition (2nd ed.). Oxford, UK: Blackwell.

Spotorno, N., Cheylus, A., Van Der Henst, J.B., \& Noveck, I. (2013). What's behind a P600? Integration Operations during Irony Processing. PLoS ONE, 8 (6), e66839.

Wilson, D. \& Sperber, D. (2004). Relevance theory. In L.R. Horn \& G. Ward (Eds.), The Handbook of Pragmatics (pp. 607-632). Oxford, UK: Blackwell Publishing.

Wilson, D. \& Sperber, D. (2012). Meaning and Relevance. Cambridge, UK: Cambridge University Press.

Uchiyama, H., Seki, A., Kageyama, H., Saito, D.N., Koeda, T., Sadato, N. (2006). Neural substrates of sarcasm: A functional magnetic resonance imaging study. Brain Research, 1124 (1), 100-110.

Utsumi, A. (2000). Verbal irony as implicit display of ironic environment: Distinguishing ironic utterances from nonirony. Fournal of Pragmatics, 32 (12), 1777-1806. 
Van Berkum, J.J.A. (2010). The brain is a prediction machine that cares about good and bad - Any implications for neuropragmatics? Italian fournal of Linguistics, 22 (1), 181-208.

Wakusawa, K., Sugiura, M., Sassa, Y., Jeong, H., Horie, K., Sato, S., \& Kawashima, R. (2007). Comprehension of implicit meanings in social situations involving irony: A functional MRI study. NeuroImage, 37 (4), 1417-1426. 